\title{
Educación en línea: un camino hacia la formación docente sin fronteras
}

\author{
Online education: a path to borderless teacher training \\ Diego Andrés Díaz-Guio,* Federico Ferrero, ${ }^{\ddagger}$ José Arturo Vázquez-Vázquez, ${ }^{\S}$ \\ Adalberto Amaya-Afanador," Yasmin Ramos, ${ }^{\circledR}$ Hugo Erick Olvera-Cortés**
}

Apreciada editora:

E s común que se plantee sinonimia entre - dos conceptos de suma importancia para quienes nos dedicamos a enseñar: Educación y Formación.

Para Émile Durkheim, padre de la sociología, la Educación es el proceso mediante el cual una generación mayor transfiere a las menores su cultura; ${ }^{1}$ en tal sentido, podríamos decir que es responsabilidad de los que están más avanzados en el proceso de aprendizaje, ayudar al crecimiento en aspectos específicos del saber a los que inician el camino. Por su parte, la Formación hace referencia a algo más preciso y estructurado, que busca imprimir un carácter a lo que es formado, en cuestiones muy concretas. Gadamer en Verdad y método, hace un rastreo al concepto Formación, y nos recuerda las palabras de $W$ von Humboldt:

Pero cuando en nuestra lengua decimos formación, nos referimos a algo más elevado e interior, al modo de percibir que procede del conocimiento y del sentimiento de toda la vida espiritual y ética, y se derrama armoniosamente sobre la sensibilidad y el carácter. ${ }^{2}$

Con esto en mente, la Federación Latinoamericana de Simulación Clínica y Seguridad del Paciente (FLASIC) por indicación de su presidente, organizó un Comité de Educación en Línea; éste fue conformado por expertos en educación y simulación clínica de cinco países (Argentina, Colombia, Costa Rica, México y Uruguay). Este equipo, a través de tecnologías de la comunicación y la información $\left(\right.$ Zoom $^{\circledR}$, WhatsApp ${ }^{\circledR}$, Marketplace de Facebook ${ }^{\circledR}$ y Google Forms ${ }^{\circledR}$ ), diseñó un plan de actividades con tópicos de alta relevancia en la educación basada en simulación, contactando a expertos temáticos de Latinoamérica, para ser los conferencistas en formato webinar de acceso libre a todos los miembros de la comunidad de FLASIC.

Desde octubre de 2018 hasta octubre de 2019, se realizaron 21 ponencias, con una duración de $53.2 \pm 9.6 \mathrm{~min}$, orientadas por 27 conferencistas de nueve países latinoamericanos (Figura 1 y Tabla 1). La dinámica se estructuró en dos partes; la inicial fue de exposición teórica, mientras que la siguiente constó de preguntas de los participantes a los expertos.

Se aplicó una encuesta anónima y voluntaria a los asistentes para calificar a los ponentes y a la sesión. Dicho instrumento contaba con 12 preguntas y cinco opciones de respuesta: muy malo, malo, regular, bueno y muy bueno. La escala presentó consistencia interna alta (Alfa de Cronbach: 0.93); fue respondida por 100 asistentes, de los cuales la mayoría fue de Argentina (37\%), Perú (23\%), México (13\%) y Chile (12\%). La calificación a los docentes fue mayoritariamente "muy buena" (Figura 2); en cuanto a la satisfacción con la sesión, 77\% la consideró "muy buena" y el restante 23\% la calificó como "buena".

Todas las conferencias se encuentran disponibles en el canal de Youtube ${ }^{\circledR}$ del comité: https://www.youtube.com/channel/

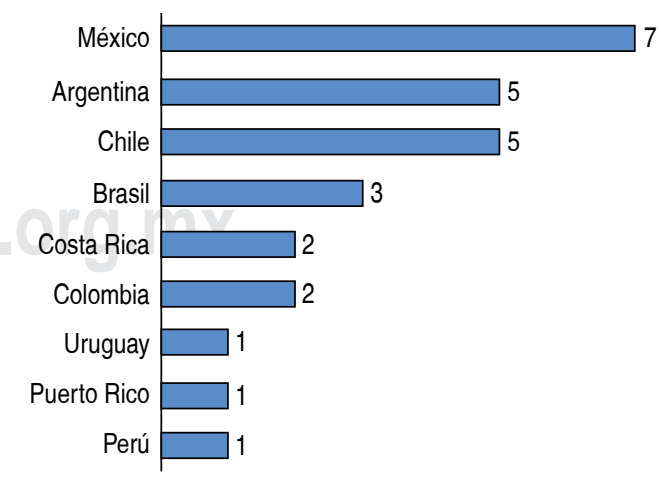

Figura 1: Frecuencia de ponentes por país. 
UC1Bs6HVikbKbKNP2UGDVEmw/videos), donde han tenido a la fecha más de 1,000 visualizaciones.

Nuestra actividad ha sido la primera experiencia en línea formal y estructurada dentro de la iniciativa de educación continuada de FLASIC. Los temas fueron pertinentes, los expositores expertos, y los participantes reportan alta percepción de aplicabilidad en la práctica. Las actividades que pretenden aprendizajes son más potentes cuando existe más interacción, ya que el aprendizaje es una actividad social. ${ }^{3,4}$ En este sentido, la consideramos satisfactoria, dado el alto número y nivel de preguntas del auditorio.

El profesional contemporáneo dispone de poco tiempo, tiene experiencia y valora lo práctico y aplicable. ${ }^{5}$ Actividades como la realizada hacen más asequibles las innovaciones y el estado del arte en

Tabla 1: Ponencias y ponentes.

Conferencia Conferencista

Investigación en simulación Inserción curricular de la simulación

Debriefing difícil

Cómo capacitar recurso humano en simulación

Pre-Briefing

Acreditación en simulación

Tips para publicar un artículo con

temas de simulación

Moulage

Cómo usar la simulación para

desarrollar HNT

Importancia de las emociones en

aprendizaje significativo

Simulación in situ

Tips para la formación de una unidad

de pacientes simulados

Coaching, Feedback y Debriefing

Ciclos rápidos de práctica deliberada

ECOE

Diseño y validación de escenarios de simulación

Gestión de un centro de simulación

Simuladores de bajo costo

Realidad virtual y simulación

Estado de la simulación en América Latina

Formación docente y evaluación
Marcia Corvetto

Sara Morales

Diego Andrés Díaz-Guio

Augusto Scalabrini

Neris Fernández

Carla Prudencio

Jorge Bustos

Darío Cecilio Fernandes

César Ruiz

Héctor Shibao

Moisés de los Santos

Juan Ignacio Cobián

Adalberto Amaya Afanador

Juan Manuel Fraga

Marlova Silva Breuer

Mónica Valenzuela

Soledad Armijo

Marcos Sandoval

José Arturo Vázquez

Víctor Hugo Pimentel

Elena Ríos

Claudio Perretta

Rafael de Oliveira Costa

Rodrigo Rubio

Ismael Ballesteros

Federico Ferrero

Yasmin Ramos

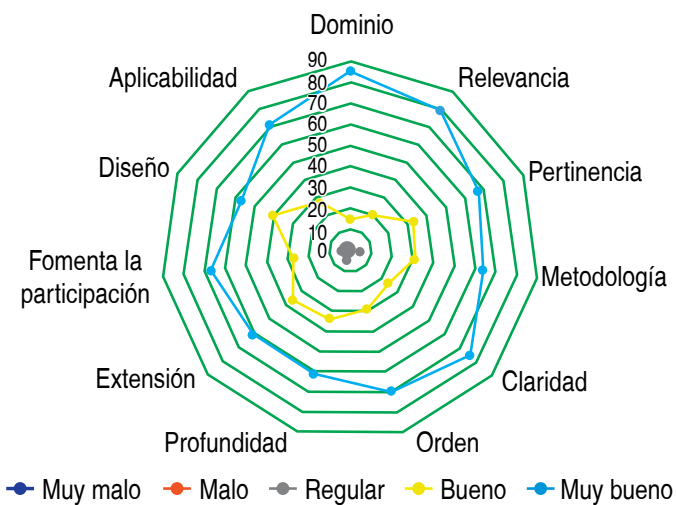

Figura 2: Proporción de calificación a los ponentes.

aspectos concretos a los profesionales; sin importar las distancias físicas en un mundo globalizado. ${ }^{6}$ Así, podemos hablar de un proceso educativo regulado, que aporta en la formación docente de quienes incursionan en el mundo de la simulación clínica.

Recomendamos ampliamente que estas labores se continúen y se mejoren, en aras de formar al recurso humano latinoamericano, sin incurrir en costos altos, para una región con economías golpeadas.

\section{AGRADECIMIENTOS}

A todos los ponentes y participantes por su apoyo.

Conflicto de intereses: Ninguno.

\section{REFERENCIAS}

1. Durkheim É. Educación como socialización. Salamanca (España): La Nouva Italia; 1973. p. 135.

2. Gadamer HG. Verdad y Método I: Fundamentos de una hermenéutica filosófica. 5a. ed. Salamanca (España): Ediciones Sigueme S.A.; 1993. p. 367.

3. Jonassen $\mathrm{DH}$. El diseño de entornos constructivistas de aprendizaje. In: Regeluth C, editor. Diseño de la instrucción: teorías y modelos un nuevo paradigma de la teoría de la instrucción. Madrid: Aula XXI; 2000. pp. 225-249.

4. Ausubel D, Novak J, Hanesian L. Psicología educativa: un punto de vista cognoscitivo. México: Editorial Trillas; 1983.

5. Knowles MS, Holton III EF, Swanson RA. Adult Learner. 6th ed. Burlington: Elsevier Inc.; 2005. p. 195.

6. Sargeant J, Curran V, Jarvis-Selinger S, Ferrier S, Allen $M$, Kirby $F$, et al. Interactive on-line continuing medical education: physicians' perceptions and experiences. J Contin Educ Health Prof. 2004; 24 (4): 227-236.

Correspondencia:

Diego Andrés Díaz-Guio

Centro de Simulación Clínica VitalCare

Armenia, Colombia.

E-mail: andres.diaz@vitalcare.co 